BREVE APRESENTAÇÃO DE “A TRANSCENDÊNCIA DO EGO-ESBOÇO DE UMA DESCRIÇÃO FENOMENOLÓGICA", DE JEAN-PAUL SARTRE

Alexandre de Oliveira Torres Carrasco.

\section{TRADUÇÃO: A TRANSCENDÊNCIA DO EGO - ESBOÇO DE UMA DESCRIÇÃO FENOMENOLÓGICA}

Jean-Paul Sartre.

\section{RESENHA: COMO TORNAR-SE LIVRE E FELIZ}

Marcos Ferreira de Paula

INSTRUÇÕES PARA OS AUTORES

CONTENTS

Marilena Chaui*

Resumo: O primeiro axioma da parte $\mathrm{V}$ da Ética de Espinosa suscita a interpretação do sujeito como espectador neutro (Macherey) ou sujeito vazio (Bove). A análise do termo "sujeito" mostra que Descartes empregava a palavra como substância, diferente da subjetividade kantiana; mas como explicar seu uso por Espinosa? A comparação desse axioma com o uso da "contrariedade" nas partes III e IV da Ética mostram em que sentido Espinosa emprega "sujeito".

Palavras-chave: sujeito, agente, substância, contrariedade, liberdade.

Este texto foi suscitado pela leitura das interpretações dadas ao primeiro axioma da Ética V por Pierre Macherey e Laurent Bove.

O primeiro axioma da Parte $\mathrm{V}$ da Ética enuncia:

"Se, em um mesmo sujeito (in eodem subjecto), são excitadas duas ações contrárias, deverá necessariamente dar-se uma mudança (mutatio) ou em ambas ou em uma só, até que deixem de ser contrárias."

Macherey descreve este axioma como definição de uma "lógica da mudança", que repousa sobre a resolução de contradições e sobre a oscilação da existência humana entre estados de equilíbrio e de instabilidade determinados por relações de forças, das quais o sujeito é apenas o ponto de aplicação sem densidade substancial e sem que ele intervenha no processo de mudança. Donde, conclui Macherey, o sujeito

"parece assistir [essas mudanças] como um espectador neutro e imparcial. O que, então, define sua identidade de sujeito? $\mathrm{O}$ fato de que, no quadro que ele oferece para o encontro

* Universidade de São Paulo. 
dessas intervenções independentes, deve necessariamente manifestar-se uma tendência à homogeneização ou à regulação que, no final, instala seja um estado de equilíbrio entre as diferentes ações seja a prevalência de uma orinetação ligada a uma única ação.” (Macherey 3, p.46)

Por seu turno, escreve Bove:

"Em sua formulação neutra: "deverá necessariamente dar-se uma mudança”. O axioma deixa aberta a interpretação sobre a natureza da determinação causal da mudança, a qual deverá necessariamente acontecer pois dessa mudança depende a continuação da existência do mesmo 'sujeito'. É como se, no início dessa Parte V (...), o primeiro axioma deixasse um branco, um vazio ao mesmo tempo como lugar de interrogação e de espera, mas também como indicação en creux de uma tarefa a cumprir, de um problema a resolver.” (Bove 1)

Para Macherey, o sujeito do axioma 1, evidentemente não substancial, é um "espectador neutro e imparcial" de uma mudança que deverá ocorrer nele. Para Bove, o sujeito é "um branco, um vazio", um "lugar de espera".

Do ponto de vista do que foi efetuado nas partes anteriores da Ética, este axioma apresenta dois problemas: em primeiro lugar, a introdução do termo "sujeito"; e, em segundo, a presença da contrariedade num mesmo sujeito.

\section{1.}

Examinemos, brevemente, o emprego do termo sujeito.

Sabemos que, na tradição filosófica de língua latina, subjectum é derivado de substare, verbo do qual se deriva substantia. Desde Sêneca e Cícero, primeiro, e de Boécio, depois, substantia foi empregada para traduzir o termo aristotélico ousía, para o qual também o latim filosófico criou um neologismo, qual seja, essentia. Ora, em latim, substare, substantia e subjectum são vocábulos da linguagem jurídica que se referem às coisas físicas ou aos corpos (é por isso que Hobbes, bom filólogo, dirá que toda substância é corporal e que é um contra-senso a idéia de substância espiritual). E se referem às coisas ou aos corpos enquanto suportes de qualidades e propriedades. Por esse motivo, no latim filosófico, subjectum foi considerado o correspondente latino do grego hupokeimenon. Ora, como nas Categorias Aristóteles distingue entre a ousía e as demais categorias e afirma que estas são predicadas àquela e a ousía não é predicada a nada, no latim, desde Boécio, isso foi traduzido como a diferença entre a substância e os acidentes, de sorte que estes são predicados a ela e ela não é predicada a nada.

Como subjectum/hupokeimenon, a substância é o suporte dos acidentes e, com a Escolástica, ela se torna o sujeito de inerência dos predicados. Por outro lado, como a ousía não é somente a substantia, mas também a essentia, esta não apenas é sujeito de inerência de predicados, mas também, e muito naturalmente, se distinguirá entre essentia formalis ou subjectum, a coisa em sua realidade externa, e essentia objectiva ou conceptus, a coisa em idéia ou o objeto como aquilo que é interno à faculdade de conhecer. Sujeito é, pois, a forma ou essência como realidade em si; objeto, a forma ou essência em nós e para nós ou como realidade pensada. Donde a distinção cartesiana entre a realidade formal e a realidade objetiva da idéia.

Como sabemos, Descartes procurará minimizar a concepção aristotélico-escolástica ao definir a substância pelo atributo principal, o qual, sendo coextensivo a ela, não é propriamente um predicado, mas sua própria essência formal, porém, ele conserva idéia de que uma substância possui predicados e entre estes encontram-se os modos da substância. Quem acompanha o percurso de Espinosa, tanto no Breve Tratado, nos 
Pensamentos Metafisicos e sobretudo na Parte I da Ética, logo compreende que ele se afasta radicalmente da tradição e mesmo de Descartes. A substância não é sujeito de inerência de predicados, nenhum atributo the é coextensivo e os modos não são seus predicados e sim suas afecções ou seus efeitos. Apesar dessa diferença de envergadura, um aspecto é comum a Descartes e a Espinosa: nunca empregam o termo subjectum para referir-se à substância. Descartes emprega res. Espinosa empregou res no Breve Tratado e emprega ens na Ética.

No entanto, é interessante observar que o termo sujeito, que tende a desaparecer nas Meditações, reaparece, por exemplo, no artigo 1 do Tratado das Paixões, no qual Descartes define ação e paixão como sendo o mesmo, o título do artigo enunciando que "o que é uma paixão em relação a um sujeito é sempre ação em qualquer outro respeito". No final desse primeiro artigo, Descartes escreve:

"considero que tudo quanto se faz ou acontece de novo é geralmente chamado pelos filósofos uma paixão em relação ao sujeito a quem acontece e uma ação com respeito àquele que faz com que aconteça; de sorte que, embora o agente e o paciente sejam amiúde muito diferentes, a ação e a paixão não deixam de ser sempre a mesma coisa com dois nomes, devido aos dois sujeitos diversos aos quais podemos relacioná-los." (Descartes 2, art.1, p.327)

É perfeitamente compreensível que Descartes assim pense, uma vez que estamos perante duas substâncias distintas - corpo e alma - e, portanto, exatamente perante dois sujeitos, um dos quais origina a ação e o outro a recebe. Podemos, assim, observar que o termo sujeito, apesar do cogito e apesar de Heidegger e Husserl, não significa a subjetividade, pois será preciso aguardar a revolução copernicana de Kant para que o caráter substancial do sujeito desapareça e sobretudo para o que se dê a famosa inversão pela qual o sujeito, ou a exterioridade, se torna o suporte interior e o objeto, ou a interioridade pensada, se torna exterioridade ou fenômeno. O Eu penso, eu sou de Descartes é subjectum e por isso mesmo, dirá Kant na Crítica da Razão Pura, ele não pode ser sujeito, isto é, pura atividade de síntese.

Se é compreensível o emprego de "sujeito" por Descartes, seu emprego não parece condizente com o pensamento de Espinosa. Não só porque este recusa que corpo e mente sejam substâncias, mas também porque recusa a identidade tradicional e cartesiana da ação e da paixão como operação reversível entre dois sujeitos. Em primeiro lugar, porque corpo e mente são passivos juntos e são ativos juntos. Em segundo, porque paixão e ação não se distinguem extrinsecamente pelos termos ad quem e ad quo, mas se diferenciam intrinsecamente por sua causalidade própria, isto é, como causa inadequada e causa adequada.

Em suma, tanto pela Parte I como pelas Partes II e III da Ética, não há como explicar a aparição do termo sujeito no axioma 1 da Parte $\mathrm{V}$, e se torna compreensível que Macherey fale num "espectador neutro e imparcial" e Bove, num "lugar vazio".

2.

Examinemos também brevemente o problema posto pelo aparecimento dos contrários num mesmo sujeito.

Ora, sabemos que o termo sujeito, antes de surgir no axioma 1, apareceu na Ética III e exatamente num enunciado que parece negar o do axioma 1. Tratase da proposição 5, cujo sentido requer o das proposições 4 e 6 .

A proposição III P4 enuncia:

"Nenhuma coisa pode ser destruída senão por uma causa externa. Demonstração: Esta proposição é patente por si; com efeito, a definição de uma coisa qualquer afirma, e não nega, 
a essência da própria coisa; ou seja, põe, e não tira, a essência da coisa. E assim, enquanto prestamos atenção à própria coisa, e não a causas externas, nada nela poderemos encontrar que possa destruí-la.”

Essa proposição afirma a positividade e indestrutibilidade intrínsecas de uma essência, de sorte que em si mesma e por si mesma permanece indefinidamente na existência e nenhuma destruição pode vir de seu interior, mas apenas da ação de causas externas.

Donde a proposição III P5:

“Coisas são naturezas contrárias, isto é, não podem estar no mesmo sujeito, enquanto uma pode destruir a outra.

Demonstração: Com efeito, se pudessem convir entre si, ou estar simultaneamente no mesmo sujeito, logo poderia dar-se no mesmo sujeito algo que poderia destruí-lo, o que (pela prop. preced.) é absurdo."

Podemos, desde já, observar que o termo sujeito é empregado por Espinosa com justeza filológica e filosófica: ele aparece justamente porque aqui Espinosa se refere àquilo que é próprio do conceito de sujeito, isto é, a inerência de predicados ou de qualidades. Assim, não pode haver simultaneamente num mesmo sujeito inerência dos contrários - "coisas de natureza contrária" - porque tais coisas se destroem reciprocamente se estiverem juntas num mesmo substrato, ou seja, o sujeito se torna contraditório e, como tal, se auto-destrói. Espinosa está empregando com perfeita exatidão e correção o princípio de não contradição tal como formulado por Aristóteles.

A conclusão dessa duas proposições é obtida com III P6:

"Cada coisa, o quanto está em suas forças, esforça-se para perseverar em seu ser.
Demonstração: As coisas singulares são modos pelos quais os atributos de Deus se exprimem de maneira certa e determinada (pelo corol. da prop. 25 da parte I), isto é (pela prop. 34 da parte I), coisas que exprimem de maneira certa e determinada a potência de Deus, pela qual Deus é e age; e nenhuma coisa tem algo em si pelo qual possa ser destruída, ou seja, que lhe tire a existência (pela prop. 4 desta parte); ao contrário, opõe-se (pela prop. preced.) a tudo que pode tirar-lhe a existência, e por isso, o quanto pode e está em suas forças, esforça-se para perseverar em seu ser."

À luz dessas proposições, podemos compreender porque o termo sujeito aparece no axioma 1 de $E \mathrm{~V}$, ou seja, ele aí aparece como suporte de predicados contrários. No entanto, exatamente por isso, o enunciado do axioma parece negar as proposições da Parte III, uma vez que nele se afirma a presença dos contrários num mesmo sujeito e a exigência de que haja uma mutação (mutatio) em ambos ou num deles. Em outras palavras, os contrários estão no mesmo sujeito, mas em lugar da auto-destruição, afirma-se a necessidade de uma mudança num deles ou em ambos.

Ora, é preciso observar a diferença entre o que dito em EIII P 5 e em EV axioma 1. De fato, a proposição 5 fala em "coisas de natureza contrária”, mas axioma fala em "duas ações contrárias”. Ora tanto na Parte III como na Parte IV, as ações contrárias se referem aos afetos e, na Parte $\mathrm{IV}$, referem-se especificamente às forças dos afetos.

\section{Na definição 5 da Parte IV lemos:}

"Por afetos contrários entenderei, no que se seguirá, aqueles que arrastam o homem para direções diversas, ainda que sejam do mesmo gênero, como a gula e a avareza, que são espécies de amor, e que são contrários não por natureza, mas por acidente." 
Na Parte III, Espinosa define o afeto como uma afecção do corpo e a idéia dessa afecção na mente quando a afecção aumenta ou diminui, favorece ou prejudica a potência do conatus. Nem toda afecção corporal é um afeto, nem toda idéia de afecção é um afeto. Pela Parte I da Ética, sabemos que os modos são afecções dos atributos de Deus, por isso mesmo, na Parte III, ao oferecer a explicação do desejo, Espinosa afirma que uma afeç̧ão é "toda disposição de uma essência, quer inata quer adquirida, quer se conceba pelo só atributo do pensamento quer pelo só atributo da extensão, quer enfim se refira simultaneamente a ambos". Todo modo finito é uma afecção e, visto que tudo o que é, está determinado por sua natureza a produzir efeitos necessários, todo modo produz afecções e recebe afecções. Dentre as afecções do corpo e as de mente, algumas são afetos, pois é afeto apenas a afecção do corpo e a afecção da mente que aumentam ou diminuem a potência do corpo e da mente. $\mathrm{O}$ afeto se refere, portanto, à intensidade da potência de um ser humano singular. Visto que o conatus é a essência atual desse ser singular, o afeto se refere às condições aumento ou diminuição de realidade de uma essência singular como aumento ou diminuição da intensidade da potência que ela é. A paixão, enquanto paixão do ânimo, é definida como uma idéia confusa que arrasta um homem em direções contrárias. Visto que o desejo é a própria essência do homem quando determinada a fazer alguma coisa por uma afecção que nela se encontra, quando o desejo é paixão do ânimo é variável num mesmo homem, dependendo das condições de seu corpo ao ser afetado por outros, assim como das disposições dos corpos exteriores que o afetam e que ele afeta, e dependendo também das condições de sua mente. A variação e a pluralidade de desejos, explica Espinosa, não raro os faz opostos uns aos outros, e um homem, "arrastado de variadas maneiras", já "não sabe para onde voltar-se".
É essa idéia que reaparece na definição 5 da Parte IV, acrescida do complemento "por acidente". Ora, essa acidentalidade foi longamente examinada na Parte III, quando Espinosa deduz a gênese imaginativa dos afetos, isto é, a variação dos afetos tanto em decorrência do estado de nosso corpo e dos corpos exteriores que o afetam, como em decorrência da variação das partes afetadas e afetantes, pois um mesmo corpo exterior pode afetar o nosso de variadas maneiras dependendo das partes de nosso corpo afetadas por ele e vários corpos exteriores podem afetar o nosso da mesma maneira, também dependendo das partes por eles afetadas. Em outras palavras, é necessário que, afetado de uma determinada maneira por um ou vários corpos exteriores, nosso corpo experimente um determinado afeto e que nossa mente experimente o mesmo afeto. Todavia, é por acidente que, na ordem comum da Natureza (onde transcorre a experiência dos encontros fortuitos entre os corpos), um ou vários corpos afetam esta ou aquela parte de nosso corpo, de sorte que um mesmo corpo exterior pode afetar-nos de maneiras variadas e diferentes corpos exteriores afetar-nos da mesma maneira conforme as circunstâncias. Além disso, a acidentalidade do afeto assim produzido decorre do fato de que ele é uma imagem corporal (imagem de nosso corpo e imagens dos corpos exteriores) e sua idéia na mente é uma idéia imaginativa. Isto significa que os afetos, enquanto imagens e idéias imaginativas, se organizam à maneira da imaginação, ou seja, por associações causadas por semelhanças, repetição da contigüidade espacial, repetição da sucessão temporal, perda de clareza após um certo limiar espacial e temporal. Esse conjunto de circunstâncias determina necessariamente a acidentalidade de um afeto no plano da experiência imaginativa, ou seja, da paixão. Em outros termos a expressão "por acidente" significa, rigorosamente, segundo causas necessárias, pois a Parte I já demonstrou que na natureza das coisas nada há que seja contingente. 
Se a tarefa da Parte III é demonstrar a diferença intrínseca entre ser causa inadequada e ser causa adequada, ou seja, entre paixão e ação, a tarefa da Parte IV consiste em tomar os afetos contrários para medir a força deles, seja quando contrários por natureza (como alegria e tristeza, de um lado, afetos ativas e afetos passivos, de outro), seja quando contrários por acidente (afetos alegres contrários; afetos tristes contrários). Por isso mesmo, a contrariedade é posta logo na abertura de $E \mathrm{IV}$, no seu axioma, que enuncia:

"Não é dada, na natureza das coisas, nenhuma coisa singular tal que não seja dada uma outra mais forte e mais potente do que ela. Dada uma coisa qualquer, é dada outra mais potente, pela qual a primeira pode ser destruída".

O axioma põe no centro da dedução a idéia de partes da Natureza mais e menos potentes. Fundada no axioma, a proposição $E$ IV P2 enuncia:

"Padecemos na medida em que somos uma parte da Natureza que não pode ser concebida por si mesma sem as outras”.

O axioma também fundamenta a proposição $E$ IV P3:

"A força pela qual o homem persevera na existência é limitada e infinitamente superada pela potência das causas externas".

\section{E, finalmente, na proposição $E$ IV P4 é demonstrado que}

"Não pode ocorrer que o homem não seja uma parte da Natureza e que não possa sofrer outras mudanças senão aquelas que podem ser compreendidas somente por sua natureza e de que é causa adequada".
Na Parte III, no escólio da proposição E III, P3, lemos que "as paixões só se referem à mente quando esta tem algo que envolve uma negação, isto é, quando a mente é considerada como uma parte da Natureza (pars Naturae) que não pode ser percebida clara e distintamente por si mesma sem as outras partes", declaração se torna objeto de demonstração na proposição 2 da Parte IV: "somos passivos enquanto somos uma parte da Natureza (pars Naturae) que não pode ser concebida por si mesma sem as outras". Na demonstração desta proposição Espinosa usa o termo partialis para referir-se ao tipo de causalidade que opera na paixão, afirmando que somos passivos quando somos causa partialis, causa parcial, isto é, cujos efeitos não podem ser deduzidos exclusivamente das leis de nossa natureza. A paixão envolve negação porque concerne a uma parte que não pode ser concebida sem as outras e que não encontra em si mesma a causa totalis do que sente, faz ou pensa. Na Ética II, ser parte e ser causa parcial estão na origem da inadequação - no conhecimento - e, na Ética III, na origem da passividade - nos afetos. Na Ética IV, esta situação, é acrescida de duas novas determinações: a de que para cada parte singular haverá outra mais potente do que ela, e a de que a parte humana não pode ser concebida sem as outras cuja potência ultrapassa infinitamente a sua. Essas duas determinações serão o fundamento da servidão.

Na servidão, a parte se encontra sob o signo da privação e da negação, que são as marcas próprias da paixão. Privação, porque a idéia inadequada e a causa inadequada não estão aptas a dar a razão total ou a causa total do efeito, faltando-lhes auto-determinação. Negação, porque a parte não pode ser concebida sem as outras na ordem comum da Natureza. Em resumo, a origem do que se passa na parte passiva está fora dela, no que não é ela. Privação e negação transformam cada parte numa potência dependente da potência de outras partes e dessa dependência surge não só a contrariedade afetiva entre elas, mas também a contrariedade de afetos no interior de cada uma delas. 
Finalmente, na Parte III, durante a dedução dos afetos, Espinosa insiste em que uma mesma coisa pode ser, por acidente, causa de afetos contrários num mesmo homem ou em vários homens; na Parte IV, durante a dedução da servidão, Espinosa insiste em que os mesmos afetos podem arrastar um mesmo homem em direções contrárias ( caso do ciúme é exemplar, como sabemos).

Ora, Espinosa insiste na distinção entre diversum e contrarium, distinção indispensável para que a razão conheça o que "há de bom e mau nos afetos", isto é, possa medir as forças dos afetos.

Diversum é o diferente por essência (os atributos são realmente diversos; os modos finitos são realmente diversos por seus atributos e são realmente diversos deles justamente porque são efeitos deles e deles recebem a essência e a potência; paixão e ação são realmente diversas, pois diversa é sua causa). Contrarium, porém, se diz da diferença de intensidade na potência de coisas de mesma natureza, pois as coisas que nada possuem em comum não podem ser contrárias nem concordantes entre si. Em outras palavras, somente coisas de mesma natureza podem convir umas às outras ou ser contrárias umas às outras. Por isso mesmo, Espinosa demonstra que, na paixão, porque esta envolve privação e negação, os homens podem ser ou contrários ou convenientes, em contrapartida, na ação ou sob a direção da razão, concordam necessariamente.

Na medida em que o conatus é a essência atual de um ser singular, este é singular justamente porque é diversum dos demais conatus pela diferença de suas essências e visto que essência e potência são o mesmo, cada ser singular é singular porque é diverso dos demais por sua potência atual. Os diversos podem convir ou ser contrários. Convêm entre si pelo que possuem em comum (por exemplo: as partes do corpo convêm porque têm em comum a causalidade eficiente do conatus que as unifica como constituintes de um único corpo). São contrários quando, embora convenientes por suas essências ou potências (pois são todos partes da mesma potência infinita da Natureza), diferem pela intensidade de suas potências e é essa diferença que, na ordem comum da Natureza, transforma os convenientes em contrários.

Contrário, portanto, se diz das forças (vis) externas e internas cuja intensidade varia em cada parte da Natureza e que, isolada, é incomensuravelmente mais fraca do que as forças das causas externas e luta com elas para afirmar-se na existência. No caso da parte humana da Natureza, contrarium está referido às forças dos afetos, pois estes são variações na intensidade da potência singular. Assim, a contrariedade não se encontra no interior de uma essência singular - não são coisas de natureza contrária simultaneamente presentes na essência -, mas nas forças dos afetos que causam a variação da intensidade de sua potência sob os efeitos da causalidade externa de potências cujas forças são superiores e contrárias às suas - ou como enuncia o axioma 1 de EV, ações contrárias excitadas num sujeito. É exatamente a contrariedade das forças externas que fundamenta a distinção entre o bom e o mau nos afetos, ou seja, é bom o afeto que convém à nossa natureza; mau, aquele que é contrário à nossa natureza. Isso, aliás, é patente pelo enunciado de E V P10, em cujo início lemos: "durante o tempo (quandiu) em que não estamos tomados por afetos que são contrários à nossa natureza".

Eis porque o axioma 1 da Parte V não fala em coisas de natureza contrária, como enunciava a proposição 5 da Parte III, e sim em ações contrárias excitadas - no caso, afecções e afetos contrários.

3.

O axioma 1 afirma a necessidade de uma mutatio, de uma mudança que desfaça a contrariedade das ações.

Como vimos, Pierre Macherey considera o sujeito do axioma $1 \mathrm{um}$ 
"espectador neutro e imparcial" e Laurent Bove o interpreta como um "lugar vazio" - ou seja, ambos consideram o enunciado do axioma intrigante, pois Espinosa não atribui ao sujeito a tarefa de realizar a mutação.

Penso, porém, que o equívoco de Macherey e Bove decorre de tomarem o termo sujeito no sentido que terá a partir do idealismo alemão, portanto, como subjetividade e agente. Ora, Espinosa tomando o termo sujejto em sua acepção clássica e tradicional - isto é, como suporte, no caso, suporte de ações contrárias - não tem motivo nenhum para atribuir a ele a condição de agente da mutatio, pois esse suporte não é uma substância.

Cabe ao axioma 2 enunciar quem é o agente da mutação: a potência.

O segundo axioma enuncia:

"A potência de um efeito é definida pela potência de sua causa, na medida em que sua essência é explicada ou definida pela essência de sua causa.”

Espinosa acrescenta que esse axioma é evidente pela proposição 7 da Parte III, isto é, aquela que afirma a identidade da essência e da potência. Essa proposição enuncia:

"O esforço (conatus) pelo qual cada coisa se esforça para perseverar em seu ser não é nada além da essência atual da própria coisa.

Demonstração: Da essência dada de uma coisa qualquer seguem necessariamente [efeitos] (pela prop. 36 da parte I); e as coisas não podem nada outro a não ser o que segue necessariamente de sua natureza determinada (pela prop. 29 da parte I); por isso a potência de uma coisa qualquer, ou seja, o esforço pelo qual, ou sozinha ou com outras, ela faz ou esforça-se para fazer algo, isto é (pela prop. 6 desta parte), a potência, ou seja, o esforço pelo qual se esforça para perseverar em seu ser, não é nada além da essência dada da coisa, ou seja, sua essência atual".
O axioma 2 reafirma o que é posto no axioma 4 da Parte 1:

"O conhecimento do efeito depende do conhecimento da causa e o envolve."

O axioma 2 opera, portanto, com a identidade de causa, essência e potência. Temos, assim, definida a figura do agente: a potência ou essência atual da coisa singular. Caberá às quatro primeiras proposições da Parte $\mathrm{V}$ determinar que se trata do agente da liberdade, isto é, a potência da mente humana quando a mente não está externamente determinada e sim internamente disposta. Em outras palavras, as quatro primeiras proposição da Ética $\mathrm{V}$ abrem o campo da reflexão. Esta é, portanto, o ponto de partida no plano ético, porém é ponto de chegada no plano ontológico. Em outras palavras, o saber de si não é princípio da filosofia, pois é fundado e não fundante.

\section{REFERÊNCIAS BIBLIOGRÁFICAS:}

1. BOVE, L., "Puissance et prudence d'une vie comme singularité chez Spinoza". Conferência no Departamento de Filosofia, FFLCH, USP, outubro de 2008.

2. DESCARTES, Traité des passions de l'âme. Ed. Adam et Tannery, vol. XI. Paris: Vrin, 1996.

3. MACHEREY, P., Introduction à l'Éthique de Spinoza. Cinquième partie. Lês voies de la libération. P.U.F., Paris, 1994.

\section{THE POSITION OF THE AGENT OF FREEDOM IN ETHICS V}

Abstract: The first axiom of the fifth part of Spinoza's Ethics gives rise to the interpretation of the subject as a neutral spectator (Macherey) or as an empty subject (Bove). The analysis of the term "subject" shows that Descartes used to employ it as substance, in contrast to the Kantian subjectivity; but how can one explain its use by Spinoza? The comparison of this axiom with the use of "contrariety" in parts III and IV of the Ethics show us in which sense Spinoza employs the term "subject".

Keywords: subject, substance, contrariety, freedom. 


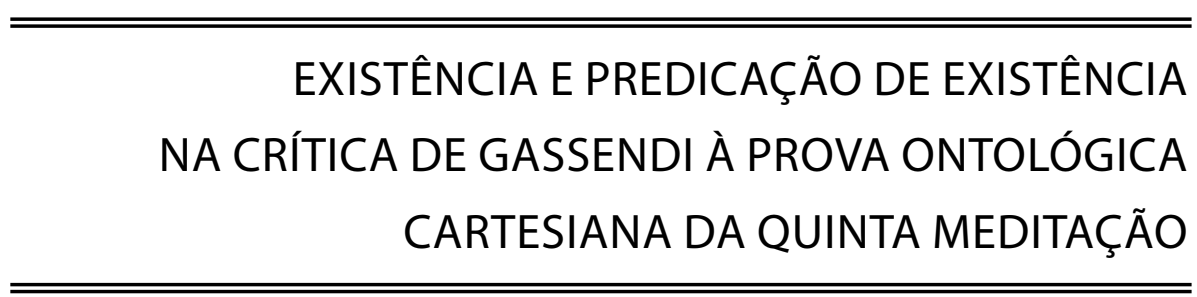

Elane Maria Farias de Carvalho*

Resumo: O objetivo deste artigo é examinar a noção de 'existência' na crítica de Gassendi à prova ontológica cartesiana da Quinta Meditação, a fim de tentar avaliar que pressupostos lógicos e metafísicos estão implicados tanto na afirmação de Gassendi segundo a qual a existência não é uma perfeição, como em sua outra objeção adicional, na qual ele utiliza a lógica dos predicáveis para combater a tese cartesiana de que a existência é uma propriedade.

Palavras-chave: Descartes, Gassendi, existência, perfeição, predicação.

Um dos pressupostos da prova a priori da existência de Deus que Descartes apresenta na Quinta Meditação é o de que a existência é uma perfeição, e é precisamente este pressuposto que Gassendi nega nas Quintas Objeções: a existência não é perfeição, mas é

“... aquilo pelo que tanto a coisa mesma quanto as [suas] perfeições são existentes, e sem o que não se diz nem que a coisa é nem que tem perfeições. Daí que [...] se a coisa carece de existência, [ela não] é dita imperfeita (ou privada de perfeição), mas sim nula." (Descartes 3,VII, 323, 15-26).

Ora, o fato é que, ao declarar nesta passagem das Quintas Objeções que uma coisa desprovida de existência nem poderia ser nem ter quaisquer perfeições, Gassendi parece se comprometer com uma tese acerca da predicação, a saber, a de que os predicados 'perfeito'e 'imperfeito' só podem ser atribuídos com verdade a coisas existentes ou, em outras palavras, que

* Prof ${ }^{a} r^{a}$ do Instituto Federal de Educação, Ciência e Tecnologia Fluminense, Campus Campos-Guarus. 